\title{
Sport-based risk management: shaping motivated, responsible and self-governing citizen subjects
}

\author{
David Ekholm \\ Journal Article
}

\section{Tweet}

N.B.: When citing this work, cite the original article.

Original Publication:

David Ekholm , Sport-based risk management: shaping motivated, responsible and selfgoverning citizen subjects, European Journal for Sport and Society, 2017. 14(1), pp.60-78. http://dx.doi.org/10.1080/16138171.2017.1284396

Copyright: Taylor \& Francis

Postprint available at: Linköping University Electronic Press

http://urn.kb.se/resolve?urn=urn:nbn:se:liu:diva-136137

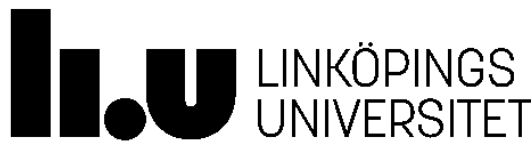




\title{
Sport-Based Risk Management: Shaping Motivated, Responsible and Self- Governing Citizen Subjects
}

\author{
David Ekholm
}

Manuscript accepted for publication, 2016-09-12

\section{Introduction}

In recent decades, sport's role in welfare provision has been made increasingly explicit, and more attention has been paid to the presumed benefits of sport in social policy (Coalter, 2007; Norberg, 2011; Silk \& Andrews, 2012). Unconventional means and arrangements for responding to social problems may be viewed in relation to the great challenges of dealing with social problems of urban segregation, social exclusion and crime that welfare provision and social work face today (Webb, 2006). This article focuses on sport as a means of responding to social problems.

In 2009 the Social and Welfare Intervention Sport Programme (henceforth SP) was launched in a large Swedish city by municipal authorities. This article examines how the governing techniques used in the programme are represented and how enactments of subject inclusion are articulated and formed. The intervention was initiated by municipal policy makers (from the leading Social Democratic Party in consensus with the other parties on the municipal council) in response to claims made by representatives of local sport clubs concerning social problems of crime and segregation in a specific urban area (henceforth the place). The SP was implemented as a local, cooperative sport-based intervention, managed by a social entrepreneur (a manager and affiliated coaches) and conducted in cooperation with municipal political administrators, local schools and sport clubs. The social entrepreneur manager runs a non-profit corporation that conducts the intervention on behalf of the municipal administration, which provides the bulk of funding. Municipal policy makers and administrators are not directly involved in the design of the practices, but they adhere to programme goals. A limited amount of funding is also provided by private sponsors. In 2016, the SP is still running in its city of origin and has also expanded to several other Swedish cities.

[The Sport Programme can] reach out to children who are not active, involve them in sport, work with social issues, integrate, gather up all youths in the risk zone, coach, educate and guide them to a better future [...] and as a result help our community and society. (Articles of Association)

The above excerpt concisely illustrates the goals of the programme: recognising youths exposed to social problems as being in the 'risk zone' of exclusion; reaching out to them by involving them in sport; as a result, 'coaching, educating and guiding' them away from risk and exclusion 'to a better future'; and through this method 'work with social issues' that help their community and society. By examining a variety of statements (in interviews, presentations, official documents and newspaper articles) from the social entrepreneur manager and representatives of the programme, recurring descriptions emerged of how 
crime and segregation were interpreted as problems, how the urban area was related to these problems, how sport was assumed to operate as a solution in response to such problems and how the targeted youths were to be made ready for social inclusion. Pedagogical measures such as 'coaching, educating and guiding' youths to become included in society were presented by representatives of the social entrepreneur as being central to the responding solution. In the following this approach will be examined in detail, namely as strategies to govern the conduct of subjects in a desirable direction (cf. Foucault, 1991; Rose, 1999). Shaping the individual as a social subject equipped with the competences needed to be included in society is notably viewed as a constitutive pedagogical dimension of social work (Philp, 1979). In the intervention examined, the response to social problems is represented as inclusion of individual subjects by means of shaping the conduct of individual subjects through governing techniques inherent in sport participation.

Starting from the premise that sport is promoted as a solution in response to social problems by means of governing the conduct of individual youths, the questions raised in this article are: (1) How are pedagogical governing techniques assumed to operate in the programme? (2) How are desirable youth citizen subjects represented as enabled for inclusion? A governmentality approach (Bacchi, 2009; Dean, 2010; Foucault, 1991; Rose, 1999) provides a theoretical framework for interpreting how individual subjects and conditions in society are constructed, problematised and made governable. In order to answer these questions, the problematisations underpinning and enabling the governing rationale need to be investigated. To provide such a background, this article also deals with what assumptions about problems and conditions in society underpin and enable the notion of sport as a means of governing. This investigation is important because it seeks to empirically examine and clarify how assertions of governing through sport may affect those subjected to such interventions, how subjects are represented to be adapted to and included in society, by what ideals they are educated and socialised into being active, responsible citizens and what is expected from them as such. One purpose of this article is to perform the empirical analysis in light of social theorising on measures in response to social problems. This may help to shed light on the conditions that enable welfare provision and social work practices today. Moreover, it may promote understanding in contemporary social policy as to how sport-based interventions govern the conduct of individual subjects and provide them with the competences needed to be included in this society.

In the next section, the concept of governmentality is introduced, providing an analytical framework for this investigation. An overview is also given of significant features of welfare provision and governing under advanced liberalism that have informed the analysis. In addition, the role of sport in welfare provision with respect to governmentality and advanced liberalism is outlined, contextualising the analysis. Methodological considerations are then discussed. The SP and the specific context of the intervention are presented, and a variety of statements related to this, comprising the empirical material examined, are explored in detail. Analytical procedures are then described and accounted for. The analysis is presented in four subsections. The first subsection covers prominent problematisations enabling means of governing. The following three subsections emphasise the SP's governing rationale with respect to the governing techniques promoted and the constructions of desirable citizens enabled for inclusion. Each of the latter subsections considers themes of motivation, 'choosing the right track' and role modelling. The article 
concludes with a reflection highlighting the main findings and relating them to recent transformations in welfare provision.

\section{Theoretical framework}

\section{Governmentality}

The governmentality approach provides a theoretical framework for analysing the inseparable relation between problem representations and responding measures of governing, how power as a productive force operates in promoting social change and how desirable citizens are formed as a result (Bacchi, 2009; Cruikshank, 1999; Dean, 2010, Foucault, 1991). The framework proposed enables a critical questioning of truth claims about problems that are taken for granted, of solutions in response to these problems, and of youths and citizenship constituting and legitimising any way of governing (Rose, 1999).

From a governmentality approach, statements are conceived of as constitutive of the objects they purport to describe (Bacchi, 2009; Foucault, 1980). Statements producing conditions of society or individual youths as problems are called problematisations; as problems and solutions presuppose each other, statements about responding solutions are constitutive of problem representations (Bacchi, 2009; Foucault, 2004). Individuals are conceived of as subjects in a twofold sense: both subjected to power (governing) and yet self-conscious and active in exercising freedom (Foucault, 1982). While being constructed as problems, conditions in society and individual subjects (and their freedom) are made possible to manage, solve and govern through various means (Bacchi, 2009; Rose, 1999). Consequently, responding to problems are governing activities in the sense that the conduct of populations or individual subjects needs to be addressed or redressed (Bacchi, 2009). For this reason, a governmentality analysis needs to recognise underlying problematisations in order to grasp the rationales of governing. Governing - broadly defined as 'the conduct of conduct' - refers to any rational activity that guides or shapes any behaviour or actions of populations or individuals (Dean, 2010; Foucault, 1982, 1991; Rose, 1999). Consequently, governing is exercised through techniques of power aimed at regulating subjects' freedom, although not necessarily by means of restrictions or limitations, but rather through productive guidance and shaping of conduct (Dean, 2010; Foucault, 1982; Rose, 1999) - for instance, in 'coaching, education and guiding' techniques that provide subjects with powers and shape the exercise of them (Rose, 1999). Such pedagogical techniques operate by means of producing and shaping subjects' subjectivities, and this is referred to as subjectification (Bacchi, 2009; Rose, 1999). The telos of governing techniques and subjectifications emerges in enactments of youths as desirable citizen subjects (Cruikshank, 1999; Dean, 2010).

According to Rose (1996a, 1996b, 1999), governing in Western societies has undergone a gradual shift from the rationales of the welfare state to those of a kind of advanced liberalism. The governmentality of the welfare state was premised on the notion of 'the social' as the dominant domain of welfare intervention. It "implied a kind of antiindividualism: the need to conceive of human beings as citizens of a wider collectivity" (Rose, 1999, 118). This governmental rationality was especially influential in Scandinavia (and Sweden) and labelled the social-democratic regime, characterised by state-centred interventionist (and expertise) social engineering (cf. Esping-Andersen, 1990). However, it has been argued that this regime is undergoing a gradual "displacement in balance" into more 
advanced liberal modes of governing (Larsson, Letell \& Thörn, 2012, 17). The move towards advanced liberalism has been described as 'the death of the social' (Rose, 1996b, 1999) or at least a mutation, rendering a "post-welfarist regime of the social" (Dean, 2010, 202). This shift in balance has been manifested in the strategies for governing the conduct of individual subjects as well as in the organisation of governing bodies. With respect to governing the conduct of individual subjects, the shift reflects a questioning of the notion that social interventions should be designated to the wider collective (Rose, 1996b). The advanced liberal diagram is instead constituted by technologies (assemblies of techniques) that enhance, promote and deploy individual agency and freedom - often promoted in terms of empowerment and activation schemes (Cruikshank, 1999; Rose, 1999). It has been argued that the techniques endorsed shape and guide subjects to make active and rational choices, to take on individual responsibility and to be active in their own governing, and in that sense regulate freedom (Dean, 2010; Rose, 1999). The technologies of agency are intimately related to rationalities of risk (Dean, 2010; Webb, 2006). Risk is, in this sense, not an objective condition; instead, it is a specific way of problematising the uncertain future by attributing dangers (Castel, 1991), to make it governable through various means of security and management to impose control and change (Ewald, 1991). These concepts provide with an analytical tool-box for exploring the rationales of sport-based governing conducted in this article.

\section{Contextualisation: sport and welfare under advanced liberalism}

With respect to the organisation of governing bodies, traditional areas of welfare provision and social work have been widely reorganised. This dimension of the shift in balance towards advanced liberalism provides a social policy context situating the examination. New mixes of welfare providers such as market- and community-based civil society actors - i.e. social entrepreneurs - and cooperative forms of governing have gained momentum (Rose, 1999; Webb, 2006). In relation, sport have by governing agencies been adopted as a means of responding to or even solving social problems (Coakley, 2011; Coalter, 2007; Heinemann, 2006), for instance, with respect to crime prevention (Nichols, 2007) and social work (Lawson, 2005). Several examples can be found, for instance: Midnight Basketball in the US (Hartmann \& Depro, 2006), Positive Futures (Crabbe, 2007; Kelly, 2011, 2012), the Sport Steward Program in the Netherlands (Spaaij, 2009), the Vencer programme in Brasil (Spaaij, 2013), DGI playground in Denmark (Agergaard, Michelsen La Cour \& Treumer Gregersen, 2015) and drive-in sports in Sweden (Stenling, 2015). However, the notion of sport's potential as a means of responding to social problems has been seriously questioned in research (Coakley, 2011; Coalter 2015; Houlihan, Bloyce \& Smith, 2009; Morgan, 2013; Verdot \& Schut, 2012). Nonetheless, sport practices with social objectives have been highlighted by policy makers because they are assumed to promote active citizenship both in terms of integrating civil society actors such as voluntary sport clubs and social entrepreneurs in welfare provision and in terms of providing means of empowerment and pro-social development for individuals (Coakley, 2011; Coalter, 2007; Lawson, 2005). In Sweden, expectations of sport's presumed benefits have been made increasingly explicit by governing agencies (Norberg, 2011). Sport practices have been assessed in terms of their estimated contribution to society and are accordingly used as a tool for governing and promoting social objectives (Fahlén \& Stenling, 2015; Norberg, 2011). This is a common international tendency (Heinemann, 2006). Such dimensions of sport in welfare provision have been interpreted as being part of advanced liberal rationales of governing in terms of 
neo-liberalism (Coakley, 2011; Hartmann \& Kwauk, 2011; Kelly, 2011, 2012; Österlind \& Wright, 2014) and the social investment perspective (Green, 2007, 2012). From a governmentality perspective, such sport-based interventions have been marked to "resemble experimental social policies aimed at governing 'the conduct of conduct' of 'unskilled' youth by equipping them with tools for self-improvement and self-management" (Hartmann \& Kwauk, 2011, 288) while “wider social and cultural aspects of 'problems' are ignored, and instead, sport is ascribed the capacity to develop desired attributes of individualism, accountability and personal responsibility as "solutions" (Österlind \& Wright, 2014, 4). Governmentality studies have been recognised as providing important insights into the relation between sport and social policy and on the role of sport in terms of governing (e.g. Agergaard \& Michelsen La Cour 2012; Green, 2012; Österlind \& Fahlén, 2015). However, this kind of sport-based social interventions has rarely been questioned with respect to the pedagogical techniques used and subject enactments promoted in relation to transitions in the traditional welfarist Scandinavian and social-democratic regime (Ekholm 2013).

\section{Empirical material and methods}

The social entrepreneur (henceforth the manager) manages and implements the SP in partnership with voluntary sport clubs and local schools on behalf of the municipal administration. The sport activities are led by coaches associated with the manager (henceforth coach 1 and coach 2) and local sport club coaches. The SP is carried out as sporting and outdoor activities during school, after school and on school holidays. Several sports are performed, among them football, basketball, boxing and dancing.

The statements articulated by representatives of the social entrepreneur (the manager, coach 1 and coach 2) analysed in this article were accessed in four ways. First, interviews were conducted. The manager was interviewed twice and the affiliated coaches were each interviewed once. The interviews were semi-structured, led by respondents' descriptions of the SP. Each interview took between 45 and 120 minutes; they were recorded and transcribed verbatim. Three of the interviews were carried out at or immediately after the sport practices performed. The initial interview with the social entrepreneur manager was carried out outside of the sport setting. The representatives all share some common background: they have practiced sport continuously in life; they are men between 20 and 30 years of age (the manager is in his late twenties; the coaches are in their early twenties); they share an immigrant background and were either born abroad or have immigrant parents; they grew up in the place or in similar urban areas in Sweden; they lack formal social work or pedagogical training or other higher education; they describe themselves as not being involved in drugs or crime but saw and were around such problems in their childhood and youth. Second, a printed copy of the social entrepreneur manager's public presentation (in PowerPoint) was accessed for the investigation. The presentation has been used in various contexts to publicly present the programme to partners and potential sponsors. Third, statements in the form of explicit quotations from the representatives in newspaper articles were included. In all 22 articles from two local papers during the years 2008-2015 were accessed. Fourth, the Articles of Association of the social entrepreneur were accessed from the Swedish Companies Registration Office. The Articles of Association include an official statement of the company's purpose and field of operation. Accordingly, the investigation has included statements made by three representatives of the programme. These three representatives were selected because they were the most actively involved in 
leading and performing the daily practices of the programme. Furthermore, the representatives interviewed are the people who articulated the statements accessed in newspaper articles. Coaches from partnering sport clubs involved in the practices were not approached since they were less active in setting up the programme as well as in leading and performing the intervention.

All statements contain self-presentations of the representatives and their practice of sport as a means of responding to social problems. For that reason, this variety of statements constitutes a comprehensive and consistent way for the representatives to talk about sport as a response to social problems with respect to this distinct case, and is accessible for examination. Although the empirical material is not extensive, it is very rich in content, enabling a thorough exploration of the rationales imbued in the variety of statements. These statements were examined in depth, and three themes were identified: representations of problems, solutions and subjects. Questions and a conceptual framework interpreting the problem-solution nexus in terms of governing were then articulated in relation to these. Guided by analytical concepts and the framework introduced, patterns and regularities were discerned. Recurring statements were systematically noted with respect to meaning and context, forming themes and sub-themes. For example, problem representations were noted to be characterised by risk rationality. Governing rationales were interpreted as containing three sub-themes with interconnected subject enactments: provision of powers and motivation, promotion of freedom of choice, and role modelling of the powers attained. Analytical concepts and framework then informed the analysis of each sub-theme, with the focus on how governing is assumed to operate and what may be produced in terms of techniques and subject enactments.

The analysis and, consequently, the theoretical framework and empirical material focus on the statements about and rationale for the programme. It is in such statements that problems, responding technologies and subject enactments are animated and that the means and ends of the intervention are formed. Consequently, it is not the actual practices that are observed or that serve as the principal object of analysis. Nor does the framework provide conceptual tools for assessing or evaluating the pedagogical practices or even for scrutinising how practices are performed in the daily routine of the programme. However, it is in such statements that the governable aspects of reality are animated and made thinkable (cf. Miller \& Rose, 1990).

\section{Analysis}

The analysis is presented in four subsections. First, the problematisations underpinning the governing rationales promoted are examined. The focus here is on the rationality of risk. Second, an analysis is made of how the motivational powers and competences needed to manage risk are provided to the youth subjects in the SP. Third, consideration is given to how subjects are motivated to use these competences in their freedom of choice - in 'choosing the right track'. Fourth, the analysis concerns how the powers, competences and freedom of choice are shaped and guided by role models in the SP. Together, the themes noted in the second, third and fourth subsections represent subsequent steps in the governing rationale assumed to operate in the programme. The rationale presented in these subsections includes both the governing techniques promoted and the desirable citizen subjects enacted. Moreover, as solutions and problem representations are intrinsically intertwined (they can only be analytically separated), implied problematisations (concerning 
for instance subject enactments) are presented in relation to the governing rationales in the latter sections.

\section{Problematisations: segregation and risk}

The problematisations of society and of subjects enabling rationales of governing first need to be examined in order to grasp the SP as a response to the social problems at hand. A key distinction was noted in the analysis between explicit problem articulations and implicit problem representations. This distinction, it will be argued, is central to the two most prominent characteristics of the problematisations - society taken for granted and the rationality of risk. Explicit articulations of structural segregation in society are exemplified here, while implicit representations are introduced and developed further in the following subsections.

In the public presentation for the programme, society is said to suffer from structural segregation, which in turn produces a range of social problems and individual risks.

Segregation and social belonging limit children's and young adults' view of the future. Segregated areas are often socioeconomically vulnerable, with higher unemployment and a larger percentage of residents who receive financial assistance than the rest of the country. [...] Studies show that children from areas with a large immigrant population have a greater risk of not qualifying for upper secondary school compared to children from other types of areas, which is explained by the social and economic structures in those areas. [...] Unemployment often leads to exclusion and destructive behaviour that causes great human suffering and substantial social costs. (Public presentation)

In one coach's statement, the characteristics of problems that are attributed to the place exposing individual youths to problems are even more significant.

It's a rough area actually. [...] I know a lot of people and I know a lot who are involved in drugs and... like bad things and all, and I've seen a lot of friends and mates [...] yeah... they got into serious trouble and I know... I can see like where they end up. (coach 1)

Three facets of segregation are articulated in the excerpts above. First, the place is distinguished as exposed to social problems, in contrast to comparable sites. Incidentally, in another excerpt, the place is referred to as "off the map, so to speak" (coach 2), indicating a peripheral relation to other parts of the city area. Second, the place is said to be populated by immigrants, which according to the excerpt intensifies the risks of young people failing in school, suffering from 'unemployment' and 'exclusion', and indulging in 'destructive behaviour'. Third, people from the place significantly lack social and economic resources, which is said to enhance their exposure to social problems. Together, these facets constitute a kind of territorial stigmatisation (cf. Wacquant, 2007), problematising the place as a particular geographical territory made ready for governing interventions. In all, such articulation produces a problematised and targeted (governable) population of excluded and marginalised deviants, presented as immigrants lacking socioeconomic resources who are peripherally localised and distinct from the rest of society. Conditions of school failure, unemployment, poverty, destructive behaviour and drugs are repeatedly identified in the statements as problems. In this sense, they are represented as consequences of segregation in society and attributed to the place. Such problems form the basis of a series of increasingly advanced social exclusion risks - as illustrated in the following excerpt and in other 
statements, from 'failing in school' and 'being unemployed' to "becoming a loser", "doing bad things", "being involved in drugs" (the manager) and 'becoming a criminal'.

It can be anything, not achieving knowledge goals [in school] but also the social aspect, daring to just be active, daring to try, daring to fail. Perhaps people have a worse sense of self-esteem and self-confidence. And it's like we say, if you don't succeed in school, then you have a hard time getting into upper secondary school, but the next step is that you don't find a job because you didn't take school seriously, and since you're unemployed, you can't get a job... then it's easy for you to get drawn into those destructive environments and become a criminal and cost society a whole lot of money. So the reason [the SP] exists is mainly to break the exclusion and really work preventively. (the manager)

Within the segregated society, risks of more advanced exclusion are ever-present. However, in the excerpt above, the problem is likewise associated with discouragement, a lack of selfesteem and self-confidence - that is, characteristics of the individual subjects rather than structural features of society. Fundamental to the programme are techniques for solving problems by means of governing individual subjects so they can achieve courage, selfesteem and self-confidence and for also shaping ('coaching, educating and guiding') the use of such powers. Although the structures of society are assumed to cause the problems at hand, they are not presented as the locus of change; instead it is implicitly the competences and agency of individual subjects that are to be subjected to change and made governable. In the following excerpt, risk is introduced as something the individual can avoid and action opportunities are represented in terms of 'choosing the right track' (while it is emphasised that change is a matter of individual attitude).

There are huge risks actually. Like... starting to take drugs and... bad things like just hanging around at night and not doing anything or like not having a job, not doing sport or having anything to do. And so... I think this is a good way to reach out to them... so that when they start doing sport they get like other ways of thinking [...] And this is a way like to get hold of these young people and make them feel that there are different tracks to choose. Choosing the right track instead... (coach 1)

The above excerpt emphasises that risk is avoidable for the individual subjects provided that they attain the powers necessary to change their 'ways of thinking' and instead 'choose the right track'. Despite social problems being explained as a consequence of social and economic structures, the solution promoted implicitly targets the agency of the individual. It is implied that the individual youth is to be subjected to change, and moreover that the youths' 'ways of thinking' are problematised and made governable.

To conclude, in order to present sport as a means of governing by focusing on technologies of agency as a feasible solution to social problems, the problem must be articulated in an engaging way, highlighting the uncertainties and potential dangers of the future. In this sense, society - and the place in particular) is depicted as being burdened with the risks of social problems and exclusion. But the risks produced from this segregation are in a sense taken for granted and viewed as inevitable conditions of society and accordingly exempted from change. Instead, those risks are assumed to be manageable and avoidable for the individual subjects; it is the individuals who are subjected to change. Provided that individual subjects attain the powers of self-esteem and self-confidence offered by 
participation in sport and seize the opportunity to change their 'ways of thinking', it is assumed they can navigate the risks and dangers of society. Such an endeavour is articulated in terms of 'choosing the right track'. Risk rationality highlights the opportunities of individual avoidance of problems and exclusion and enables the governing rationale of the SP to focus on motivational powers, freedom of choice and the shaping of appropriate competences.

\section{Governing rationales: motivation}

The rationality of risk, introduced above, is intertwined with powers of self-esteem and selfconfidence, which are viewed as necessary to avoid social problems and exclusion. These powers are associated with enabling the individual agency of youths and are assumed to be provided by means of sport participation. The following excerpt directs our attention to the SP's will to empower in such regards.

What does [the SP] want to achieve with its target audience? [...] Goal. Increased selfconfidence: believe in one's ability to carry out things; Increased self-esteem: feel seen and confirmed for what one is [...] give children and youths resources and tools so they can find the right track at an early age. [...] [SP activities] enable children to take school seriously and avoid destructive environments. (Public presentation)

From this statement, the desired citizen subject is enacted as one who is active and motivated and believes in his/her ability to navigate away from 'destructive environments'. To be active, though, the subject must be provided 'tools and resources' - competences and powers - such as self-confidence and self-esteem which can be used to navigate in life. Furthermore, another excerpt indicates that these powers are viewed as fundamental capacities that are sufficient for the "courage to break bad habits [...] courage to say no [and] courage to initiate [healthy] social relations" (the manager in a newspaper article), competences that are presumably needed to avoid risk. Powers and competences are provided since the youths are 'seen and confirmed for being who they are'. Such a notion highlights the importance of authentic social relations between the youth subjects and the coaches and role models in the programme. In another quote from coach 1, the lack of powers of self-esteem, self-confidence and the courage to say no is articulated as "[lack of] ability to resist group pressure [and] be able to decide for yourself and to be autonomous". In this sense, the problem is not only represented as being directed towards the individual but also specified in terms of a lack of distinct powers and a lack of autonomy that are assumed to enhance exposure to risk, social problems and more advanced exclusion. Being attributed as powerless and dependent on others (or on welfare interventions in general) adds to and consolidates the problematisation of the targeted youths' spatial, ethnic and socioeconomic marginalisation. Being autonomous, motivated and able to make active decisions are represented as virtuous competences enacted in the subjects and vital in 'choosing the right track'.

To sum up, the SP is assumed to provide the subjects with motivation, competences and the powers of self-esteem and self-confidence that are necessary to navigate and avoid risks. Accordingly, the subjects are problematised as lacking these powers, and the desired subject enacted instead is motivated, empowered and autonomous. 


\section{Governing rationales: 'choosing the right track'}

When empowered with self-esteem and self-confidence, the subjects are urged to use these powers in seizing opportunities and making active choices. This exercise is articulated as 'choosing the right track'; similarly, welfare and inclusion in terms of navigating and avoiding risk are represented as a matter of choice. In the following two excerpts, the importance of choice and seizing opportunities is emphasised in relation to powers of selfesteem and self-confidence.

It is important to get children and youths to believe in their own ability. To do so, they have to have role model leisure activities. If there are none, it is easy for children to be attracted to these destructive forces. If they can start early, it is easier for them to get a sense of self-esteem and decide that crime is not for them. (the manager in a newspaper article)

We want to give young people different alternatives and get them to realise what opportunities they have. It can also be a matter of starting with sport instead of winding up on the wrong track. (coach 1 in newspaper article)

In these excerpts, sport is presented as an alternative to the deficiencies and risks of segregated society: there are, so to speak, dangers and forces out there that sport can be an alternative track to. However, being active (in terms of sport participation) is assumed to divert young people from these dangers and forces provided that they obtain the powers offered and actively use them in the 'right' way. Failing in this quest is presented as a consequence of both passivation (in terms of an inability to choose) and misguided activation (in terms of making bad choices). In the following excerpt, passivation is associated with a lack of self-esteem and self-confidence as well as an inability to choose track, which enhances the risk of more advanced exclusion. This is articulated in terms of 'drift $[$ ing $]$ into destructive environments and become a criminal'.

Maybe you lack self-esteem and self-confidence. And as we say, if you don't make it in school, you have a hard time getting into upper secondary school, or if you get into upper secondary school, the next step is that you can't find a job since you didn't take school seriously so you are unemployed... you have no job... then it's easy to drift into destructive environments and become a criminal or cost society a whole lot of money. (the manager)

If youths are not able to choose or seize the opportunities provided, they risk drifting into more advanced exclusion and ending up in crime. Consequently, it is suggested that individuals need to be able to navigate risks by 'choosing the right track'. Not 'choosing the right track' is assumed to result in passivity and exposure to the dangers of the segregated society. In this sense, passivation is implicitly introduced as a problematised condition intertwined in the powerlessness attributed to the targeted youth. Second, destructive forces in the surrounding environment in the place are said to offer youths affection. Together with representations of passivation, misguided activation is associated with deviant role models in the following excerpt.

Many guys don't have a dad or their dad doesn't have time for the kids, so they look for male role models and... I mean, what I could see when I was young, it's like there were a lot of pizzerias, nothing wrong with that but that was nothing I wanted to be. You could see that there wasn't much to living on social assistance, nothing wrong with that 
as such or... obviously it's wrong... But I mean it's not what I wanted. And then there was the criminal life [...] And the picture you give younger people then, that it's cool to have been in prison. And what that does when some younger kid says, 'shit what a big brother, cool down, he's got an iPhone, he's got girls, he's got a lot of money and he even has... he's got muscles because he's been in prison'. And then you have someone... who says, 'God, I'm going to be like that big brother too'. So they look up to the guy even though it's totally the wrong way. So that's the main problem we see. That usually when you're unemployed and have nothing to do, it's easy to say... okay, you have to survive. Because everyone wants to be seen and everyone wants to be noticed and confirmed. And if they don't find the right signals, then they find these things. [...] And that's pretty much the picture I want to show, that there are a lot of other things than these destructive environments. (the manager)

Here, passivation such as being dependent on welfare support or working in low-status jobs are stigmatised. It is suggested that people who are passivised lack the ability to be autonomous and master their own lives - the manager's self-presentation is distinctly disassociated from such images. However, representations of deviant influences promoting misguided activation are more prominent. Criminals (in the archetype of 'the big brother') that allegedly inhabit the place are depicted as deviant role models introducing bad choices and misguided activity. They offer tempting images of girls, money, electronic devices and physical attributes as well as affection and confirmation. In contrast to surrounding environments, the SP is presented as providing another kind of (positive) role models (elaborated in the next section). However, most notably, an opportunity is presented - be it as an alternative to passivation or misguided activation - to divert the youths from deviancy and risk by 'choosing the right track'. Furthermore, the context surrounding the SP and the SP itself are described as masculine domains. Although it is not often specified, as in the excerpt above, the role models in the SP are men, the absent role models are men, the deviant influences are men, the enactment of subjects are implicitly masculine and the characteristics represented are nurtured by masculine discourses of power, discipline and autonomy as well as drugs, violence and crime (cf. Messner, 1992).

The targeted and problematised youths are not explicitly assigned responsibility for being at risk of social problems; however, while inclusion is represented as an avoidance of inherent risk and as a matter of individual agency and choice, the subjects are enacted as being responsible for their welfare - both in terms of success (inclusion) and failure (more advanced exclusion). In this sense, life in the place is enacted as a domain where subjects are supposed to calculate costs and benefits from decision-making and where deviance and exclusion are represented as consequences of bad decisions or the inability to make decisions (passivation).

The governing rationale in play here concerns changing the subjects' subjectivities; they are 'coached, educated and guided' to change 'their ways of thinking' and to take responsibility for their actions. However, the SP's governing rationale does not liberate their subjects in these terms from constraints of making free choices; rather, it forces freedom of choice on the subjects. From this point of view, they are "not merely 'free to choose' but obliged to be free, to understand and enact their lives in terms of choice" (Rose, 1999, 87). In this sense, "they have to be made free in a process that entails the transformation of educational practices to inculcate certain attitudes and values of enterprise" (Rose, 1999, 65). This 
inculcation of values is facilitated by role models, which shape these powers of freedom, and will be analysed further.

To sum up, the SP representatives present welfare and inclusion as a matter of choice ('choosing the right track'). In addition, the youths in the place are problematised as being passive and unable to actively choose or misguided in their activities and choices, whereas sport participation is presented as providing powers, opportunities and guidance to avoid more advanced exclusion. In line with this, the targeted subjects are enacted to embrace freedom of choice, to approach opportunities as rational and calculative agents pursuing their own interests while accepting responsibility for gaining welfare and inclusion.

\section{Governing rationales: role models}

The SP's governing rationale has been presented to provide subjects with the powers necessary to navigate in society and avoid risks and moreover to impose freedom of choice as a condition for welfare and inclusion. In order to shape these powers and guide freedom of choice, role models emerge as a facilitating force - and the SP is presented as providing exemplary role models who emphasise good behaviour and character as well as embodying entrepreneurial skills and self-governing abilities providing dreams of social mobility. In the following excerpt, the merits of the SP role models are highlighted.

[The SP] coaches have a deep understanding of the targeted population and often come from that group, they have a "degree from the university of the streets". The coaches are credible role models who demonstrate that it is possible to change one's future. (Public presentation)

The representatives of the social entrepreneur present themselves as positive role models who 'have a deep understanding of the targeted population' and share a common history, with 'degree from the university of the streets' and are credible in demonstrating 'that it is possible to change one's future' (social entrepreneur's Public presentation). They are portrayed as humane, authentic and anti-authoritarian and motivating the subjects. In this sense, it is implicitly beneficial that the coaches are not trained social work or pedagogy professionals; instead, they are influential based on their authenticity and common history, and because they have proven that they can navigate risks and have succeeded in 'choosing the right track'. The following excerpt links to the facilitating force of role models while emphasising freedom of choice.

You could sort of choose tracks... and I chose... I like had basketball, so I started early in basketball... so I chose... I knew what track to choose. [...] I still hung around with the kind of people that... so it was easy to choose the wrong road. [...] At that age, they chose drugs and decided to not give a shit about school like and steal things and rubbish like that. [...] Us coaches here, we've also had... not really a rough background, but we've had to choose tracks. And most of us chose this track. (coach 2)

In the excerpt, the coach presents himself and the other role models as representatives of an entrepreneurial force in both pursuing challenging opportunities and coaching in the programme (as does the manager in setting it up). Role models are presented as guiding and shaping the conduct of the subjects in providing a frame for the subjects exercising their freedom by successfully navigating risks in society. They have shown their entrepreneurial strengths in successful navigation, their self-esteem and self-confidence, 
their courage to reject passivation and exclusion, their risk management, their acceptance of freedom and responsibility - they enact themselves by articulating themselves as entrepreneurs of their own future and welfare. This is the imperative of youths subjected to SP intervention: the role-modelling entrepreneurial representatives induce the subjects to choose the same track to welfare and inclusion that they themselves chose. Moreover, discipline and self-governing emerge as competences needed for entrepreneurial navigation. In the following excerpt, the social entrepreneur manager illustrates the importance of agency and individual responsibility - in his capacity as a role model - in subjecting himself to regulatory practices such as 'plan, prepare well in advance and to be on time'.

I had to fight to rise in Swedish society. I was lucky, but I'm an example of how nothing is impossible. I've learnt to see to myself, plan, prepare well in advance and to be on time. (the manager in a newspaper article)

Individual change is reflected in the imperative of regulating one's own freedom. Inclusion is apparently available by struggling hard and disciplining oneself. In all, attaining powers of the self, accepting freedom of choice and the responsibility this entails illustrate a capital telos of the SP pedagogy and governing rationale: self-regulation and self-governing. The targeted subjects are urged to exercise power over themselves, to regulate and govern their freedom. In other words, the strategy is to do like the role model: exercise discipline and take care of oneself, and one will be able to make 'good choices' and gain inclusion. In this sense, the governing rationale is to produce responsible citizens, who are active in their own governing. There is a paradoxical feature here. The imperative is to become autonomous and self-governing; the means promoted to achieve this is to follow in the role model's steps and make the same choices. In addition, gaining competences of entrepreneurship and self-regulation enables a person to follow in the role model's steps as is illustrated below.

So what I mean is exactly this... if I can, then you can too. Many children think that way... 'but I'll never succeed at this because... either because... I'm an immigrant, my mum and dad aren't rich, I'm not very good at school, that wouldn't happen to me etc. etc.'. Instead, people say 'that's not possible'. But what I want to show is that everything is possible. So it's a lot of storytelling when I say... okay, you come from war and you think it's not possible to get a job. 'No, but wait, I come from war. I got a job... I'm an immigrant and I met the King. What's the difference between you and me?' And when they start thinking themselves, they see that, 'but no ... shit, I can meet the King too and I can take that course'. [...] So much of it is about simply inspiring children and telling your own story. Telling about how... even if you live in an area you actually have... there are opportunities you can... what is the word... that you can be something. (the manager)

The excerpt emphasises what is at stake for targeted youth if they gain the necessary powers, accept freedom of choice and shape themselves in line with the role models given. Education and jobs represent successful navigation away from more advanced exclusion; meeting the Swedish King is the equivalent of such success. It is noteworthy that such inclusion is possible, as is shown in the manager's self-presentation and own 'storytelling' of his life as subjects follow the trodden path of the role models in general and the manager in particular. In the eyes of the manager, this opportunity has no limits in terms of spatial, ethnic or socioeconomic marginalisation, but instead invites subjects to move away from 
the risk of exclusion to inclusion. In this sense, the SP is about constructing a narrative of success and governing by means of subjecting youths to that narrative.

To conclude, from an analysis of the statements of the SP's representatives, the subjects are enacted as incarnations of the role models: they are entrepreneurial in seizing opportunities to navigate and avoid the risks that society decrees; able (and enabled) to discipline and govern their own conduct - to take care of themselves and gain mobility opportunities and inclusion. From this it is implied that the SP can help subjects help themselves to manage their own risks by providing the powers that are necessary and by shaping the subjects' subjectivities in a desirable direction.

\section{Concluding reflections}

The analysis examined the techniques promoted and the subject enactments produced in statements. SP participation is associated with technologies of agency that presumably lead to individual change in three interrelated steps. First, participation is presented as providing subjects with motivational powers of self-esteem, self-confidence and the courage to say no. Second, subjects are encouraged to use these powers in making active and free choices to navigate and avoid risks of social problems and more advanced exclusion. Third, shaping the powers of freedom used is facilitated by means of role models, who themselves have already chosen the right track. They model the entrepreneurial skills and discipline necessary as well as promote social mobility conditional upon such competences. In this respect, desirable citizen subjects are enacted as incarnations of the role models: active and motivated, embracing freedom of choice, rational and calculative in pursuing their interests and competent in 'choosing the right track', entrepreneurial, self-regulating, self-governing, and accepting of responsibility and accountability for their own mobility, inclusion and welfare. Consequently, the governing rationale and subjectification effect are enabled by spatial, ethnic and socioeconomic problematisations of the place and of the targeted population. However, the individual youths that populate the place are represented as the subjects of change and thus made governable: they implicitly lack the power, resources and character to control their future and welfare - which exacerbates and consolidates the structural exclusion they are subjected to. Moreover, problems and exclusion are presented in terms of risk. Risk represents a specific type of problematisation which introduces individual avoidance as an opportunity and appeals to powers of the self and entrepreneurial skills that are used in rational, competent choices.

There is an obvious inconsistency in explaining the causes of social problems beyond the individual, in the structures of society, while attributing potential solutions to individual action. By introducing the technologies of agency and rationalities of risk as being intertwined, the problem is displaced from 'the social' to the individual subject. In this inconsistency, risk management, which reduces predicted and calculated harms, emerges as a key feature of the SP, instead of focus being placed on the proposed causes of problems (various dimensions of segregation). Perhaps these could be complementary strategies; however, the domain made governable does not concern the segregated society. Instead, change is by means of technologies of agency imposed on the individual subjects. In this sense, a narrative is constructed around sport participation enlivening a dream of individual mobility and inclusion opportunities (cf. Coakley, 2002) that aligns with a dominant paradigm of advanced liberal social policy. 
Conceptions of problems, solutions and individual subjects in the statements analysed, which emphasise targeted populations, risk, individual change, motivational empowerment, agency in choice, responsibilisation and self-governing imperatives, are not unique in any way. Instead, interventions underpinned by such notions have emerged as standard solutions in contemporary - advanced liberal - society. It can be argued that the SP exemplifies the shift from governing rationales of the welfare state to those of advanced liberalism. Individual activation and responsibility mirror a privatisation of risk management, in contrast to the welfare state diagram of socialised risk insurance (cf. Esping-Andersen, 1990). Because the governing technologies are aimed at promoting social change through the shaping of individual subjects' freely made choices and self-regulatory practices ('choosing the right track') and not through collective manipulation, the rationale mirrors a mutation of 'the social'. This, of course, is intertwined in terms of relocating agency from state-centred provision: it is individual subjects who are activated to be the entrepreneurial agent and manager of their own risk and welfare. Notably, power is exercised through the guidance of actions and behaviours, the production of conduct and the formation of subjectivity. By addressing the subjects' powers of freedom through the promoted techniques of 'coaching, education and guiding', conduct and subjectivity are strictly engineered with envisaged outcomes. Distinct from welfare-statist social engineering, the rationales associated with the SP would rather be conceived of as "advanced liberal engineering" (Thörn \& Larsson, 2012, 281) - engineering the powers of freedom to produce responsibilised, self-governing citizen subjects. This kind of governing is performed by a mix of welfare providers at a distance from statist and municipal agencies.

Nonetheless, viewing the problematisations and governing rationales as mirroring advanced liberal governmentalities and subject enactments is not the same as saying that representatives of the social entrepreneur explicitly advocate this. Rather, such an interpretation more likely indicates how such discourse has been established as commonsense understanding of social problems and responding solutions - and even our understanding of 'sport' when attributed the potential as a means of responding to social problems - and how that shapes the statements produced. It is in the context of advanced liberalism that the representatives' notions and conceptions of problems and solutions are formed. In this sense, they can be conceived of as being subjected to such an advanced liberal kind of discourse. Governing here operates most effectively by enforcing specific problematisations, frames for interpretation and subjectifications in order to impose designated regimes of governing.

To conclude this reflection, empirical accounts of contemporary governing techniques in a sport-based social and welfare intervention have been provided - together with some instances of how welfare provision may be enabled and performed today. Three steps of governing rationales, enactments of desirable citizen subjects and the problematisations enabling them have been highlighted in the specific case of a sport-based social and welfare intervention. In addition, the governing rationale of the SP illustrates one instance among a multitude of how the Swedish social-democratic welfare regime is mutating under the transition from welfarism to advanced liberalism, moreover highlighting the role of sport with a focus on subject formation and social inclusion. 


\section{REFERENCES}

Agergaard, S. \& Michelsen la Cour, A. (2012). Governing Integration through Sports. A Case Study of Civil Society Involvement in Welfare Policy. Nordic Journal of Migration Research, 2/1, 26-34.

Agergaard, S., Michelsen la Cour, A. \& Treumer Gregersen, M. (2015). Politicisation of migrant leisure: a public and civil intervention involving organised sport. Leisure Studies, 35/2, 200-214.

Bacchi, C. (2009). Analysing policy: what's the problem represented to be? Frenchs Forest: Pearson.

Castel, R. (1991). From Dangerousness to Risk. In G. Burchell, C. Gordon \& P. Miller (Eds.), The Foucault Effect. Studies in Governmentality (281-298). Chicago: University of Chicago Press.

Coakley, J. (2002). Using sports to control deviance and violence among youths: Let's be critical and cautious. In M. Gatz, M. Messner \& S. J. Ball-Rokeach (Eds.), Paradoxes of youth and sport (13-30). Albany: State University of New York Press.

Coakley, J. (2011). Youth sports: What counts as “positive development?”. Journal of Sport and Social Issues, 35/3, 306-324.

Coalter, F. (2007). A wider social role for sport: Who's keeping the score? London: Routledge.

Coalter, F. (2015). Sport-for-change: Some Thoughts from a Sceptic. Social Inclusion, 3/3, $19-23$.

Crabbe, T. (2007). Reaching the 'hard to reach': Engagement, relationship building and social control in sport based social inclusion work. International Journal of Sport Management and Marketing, 2/1-2, 27-40.

Cruikshank, B. (1999). The will to Empower. New York: Cornell University Press.

Dean, M. (2010). Governmentality. Power and Rule in the Modern Society, $2^{\text {nd }}$ edition. London: SAGE.

Ekholm, D. (2013). Research on Sport as a Means of Crime Prevention in a Swedish Welfare Context: A Literature Review. Scandinavian Sport Studies Forum 4, 91-120.

Esping-Andersen, G. (1990). Three worlds of welfare capitalism. Cambridge: Polity Press.

Ewald, F. (1991). Insurance and Risk. In G. Burchell, C. Gordon \& P. Miller (Eds.), The Foucault Effect. Studies in Governmentality (197-210). Chicago: University of Chicago Press.

Fahlén, J. \& Stenling, C. (2015). Sport policy in Sweden. International Journal of Sport Policy and Politics, 1-17. 
Foucault, M. (1980). Truth and Power. In C. Gordon (Ed.), Power/Knowledge, selected interviews and other writings 1972-1977. Harlow, England: Harvester Press Limited.

Foucault, M. (1982). The Subject and Power. Critical Inquiry 8/4, 777-795.

Foucault, M. (1991). Governmentality. In G. Burchell, C. Gordon \& P. Miller (Eds.), The Foucault Effect. Studies in Governmentality (87-104). Chicago: University of Chicago Press.

Foucault, M. (2004). Polemics, Politics, and Problematizations. An Interview with Michel Foucault. In P. Rabinow (Ed.), The Foucault reader: an introduction to Foucault's thought (381390). London: Penguin Books.

Green, M. (2007). Governing under advanced liberalism: sport policy and the social investment state. Policy Sciences, 40, 55-71.

Green, M. (2012). Advanced Liberal Government, Sport Policy, and "Building the Active Citizen”. In D. L. Andrews \& M. L. Silk (Eds.), Sport and Neoliberalism. Politics, Consumption, and Culture (38-56). Philadelphia: Temple University Press.

Hartmann, D. \& Depro, B. (2006). Rethinking sports-based community crime prevention. A preliminary analysis of the relationship between midnight basketball and urban crime rates. Journal of Sport and Social Issues, 30/2, 180-196.

Hartmann, D. \& Kwauk, C. (2011). Sport and development: An overview, critique, and reconstruction. Journal of Sport and Social Issues, 35/3, 284-305.

Heinemann, K. (2006). Sport and the welfare state in Europe. European Journal of Sport Science 5/4, 181-188.

Houlihan, B., Bloyce, D. \& Smith, A. (2009). Editorial: Developing a Research Agenda in Sport Policy. International Journal of Sport Policy, 1/1, 1-12.

Kelly, L. (2011). 'Social inclusion' through sports-based interventions? Critical Social Policy, $31 / 1,126-150$.

Kelly, L. (2012). Sports-based interventions and the local governance of youth crime and antisocial behavior. Journal of Sport and Social Issues, 37/3, 261-283.

Larsson, B., Letell, M. \& Thörn, H. (2012). Transformations of the Swedish Welfare State: Social Engineering, Governance and Governmentality. An introduction. In B. Larsson, M. Letell \& H. Thörn (Eds.), Transformations of the Swedish Welfare State (3-22). New York: Palgrave MacMillan.

Lawson, H. A. (2005). Empowering people, facilitating community development, and contributing to sustainable development: The social work of sport, exercise, and physical education programs. Sport, Education and Society, 10/1, 135-160.

Messner, M. (1992). Power at play: Sports and the problem of masculinity. Boston: Beacon. 
Miller, P. \& Rose, N. (1990). Governing Economic Life. Economy and Society, 19/1, 1-31.

Morgan, H. (2013). Sport Volunteering, Active Citizenship and Social Capital Enhancement: What Role in 'Big Society'? International Journal of Sport Policy and Politics, 5/3, 381-395.

Nichols, G. (2007). Sport and crime reduction: The role of sports in tackling youth crime. London: New York: Routledge.

Norberg, J. R. (2011). A Contract Reconsidered? Changes in the Swedish State's Relation to the Sports Movement. International Journal of Sport Policy and Politics, 3, 311-325.

Österlind, M. \& Fahlén, J. (2015). Reconsidering the Epistemology of the Swedish Sports Model through the Lens of Governmentality: Notes on the State-Civil Society

Relationship, Government, Power and Social Change. Idrott, Historia \& Sambälle. Svenska idrottshistorisk a föreningens årsskrift, 2015, 148-170.

Österlind, M. \& Wright, J. (2014). If sport's the solution then what's the problem? The social significance of sport in the moral governing of 'good' and 'healthy' citizens in Sweden, 1922-1998. Sport, Education and Society, 19/4, 973-990.

Philp, M. (1979). Notes on the form of knowledge in social work. The Sociological Review $27 / 1,83-111$.

Rose, N. (1996a). Governing "advanced” liberal democracies. In A. Barry, T. Osborne \& N. Rose (Eds.), Foucault and Political Reason. Liberalism, neo-liberalism and rationalities of government (37-64). Chicago: University of Chicago Press.

Rose, N. (1996b). The death of the social? Re-figuring the territory of government. Economy and Society, 25/3, 327-356.

Rose, N. (1999). Powers of Freedom: reframing political thought. Cambridge: Cambridge University Press.

Silk, M. L. \& Andrews, D. L. (2012). Sport and the Neoliberal Conjuncture: Complicating the Consensus. In D. L. Andrews \& M. L. Silk (Eds.), Sport and Neoliberalism. Politics, Consumption, and Culture (1-22). Philadelphia: Temple University Press.

Spaaij, R. (2009). Sport as a vehicle for social mobility and regulation of disadvantaged urban youth: Lessons from Rotterdam. International Review for the Sociology of Sport, 44/2-3, 247-264.

Spaaij, R. (2013). Changing people's lives for the better? Social mobility through sportbased intervention programmes: opportunities and constraints. European Journal for Sport and Society, 10/1, 53-73.

Stenling, C. (2015). The Drive for Change: Putting the Means and Ends of Sport at Stake in the Organizing of Swedish Voluntary Sport. Umeå: Print \& Media. 
Thörn, H. \& Larsson, B. (2012). Conclusions: Re-Engineering the Swedish Welfare State. In B. Larsson, M. Letell \& H. Thörn (Eds.), Transformations of the Swedish Welfare State (262282). New York: Palgrave MacMillan.

Verdot, C. \& Schut, P. O. (2012). Sport and Social Inclusion: The Political Position vs. Practices. European Journal for Sport and Society, 9/3, 203-227.

Waquant, L. (2007). Territorial Stigmatization in the Age of Advanced Marginality. Thesis Eleven, 91/1, 66-77.

Webb, S. A. (2006). Social work in a risk society. Social and Political Perspectives. New York: Palgrave MacMillan. 